\title{
The Social and Psychological Effects of Inclusive Education of Persons with Hearing Disability in Society: A Field Study at the Disability Resource Centre (Sharjah University)
}

\author{
Nagwa Babiker Abdalla Yousif ${ }^{1, *}$, Enaam Mohammed Yousef ${ }^{1,2}$ and Rasha Mohamed Abdelrahman ${ }^{3}$ \\ 1 Department of Sociology, College of Humanities and Sciences, Ajman University, \\ Ajman 346, United Arab Emirates; e.youssef@ajman.ac.ae \\ 2 Department of Sociology, Ain Shams University, Cairo 11566, Egypt \\ 3 Department of Psychology, College of Humanities and Sciences, Ajman University, \\ Ajman 346, United Arab Emirates; r.abdelrahman@ajman.ac.ae \\ * Correspondence: nagwabfatima@gmail.com
}

\section{check for} updates

Citation: Yousif, N.B.A.; Yousef, E.M.; Abdelrahman, R.M. The Social and Psychological Effects of Inclusive Education of Persons with Hearing Disability in Society: A Field Study at the Disability Resource Centre (Sharjah University). Sustainability 2021, 13, 12823. https://doi.org/ $10.3390 /$ su132212823

Academic Editors: Luis Ortiz Jiménez and Juan Carrión José Martinez

Received: 6 September 2021

Accepted: 10 November 2021

Published: 19 November 2021

Publisher's Note: MDPI stays neutral with regard to jurisdictional claims in published maps and institutional affiliations.

Copyright: (c) 2021 by the authors. Licensee MDPI, Basel, Switzerland. This article is an open access article distributed under the terms and conditions of the Creative Commons Attribution (CC BY) license (https:/ / creativecommons.org/licenses/by/ $4.0 /)$.

\begin{abstract}
The objective of inclusive education is to increase the quality of social and psychological integration in society of students with disabilities in the learning process. This study aimed to identify the social and psychological effects of inclusive education of students with hearing disabilities at Sharjah University's Disability Resource Centre. The study adopted a descriptive analytical approach with a purposive sample comprising 24 students with hearing impairment. An electronic questionnaire comprising 25 psychological and social statements and nine open-ended questions was administered to collect quantitative and qualitative data. The results revealed positive correlation coefficients between inclusive education and both psychological adjustment and social interaction and negative relationships between gender and age and both social interaction and psychological adaptation variables (for age $\rho=0.091$ and $\rho=0.262$ and for gender $\rho=0.47$ and $\rho=0.076$, respectively). A statistically significant difference of less than 0.05 was found in favour of those who agreed that inclusion affects psychological adaptation. A statistically significant difference of less than 0.05 was found in favour of students who agreed that inclusion affects social interaction. The research results can be used in the practice of inclusive education to determine ways to improve the social and psychological adaptation of students with hearing impairments.
\end{abstract}

Keywords: inclusive; social effect; psychological effect; hearing impairment; education

\section{Introduction}

The number of individuals with hearing and disabilities is increasing; the World Health Organization (WHO) recently estimated that "there are currently about 466 million people suffering from impaired hearing in the world, with the aging of the world population, the number of people suffering from hearing loss will increase at a rapid rate. The World Health Organization projects that, unless action is taken, there will be 630 million people with impaired hearing loss by 2030, and that number is expected to increase to more than 900 million by 2050" [1].

Inclusive education for people with special needs has developed and had an impact during the past 26 years. UNESCO declared in 1994 that development of inclusive education is an issue of equal importance for the countries of the North and the South. This goal cannot be achieved in isolation. It should be part of the new educational, social, and economic policy. The main reform should be the reform of the regular school [2].

The World Conference on the Education of People with Special Needs was held in June 2019 in Salamanca, organized by UNESCO and the Ministry of Education and Science in Spain, and published as the Salamanca Statement and Framework for Action Concerning the Education of People with Special Needs, which is a crucial international document 
in the field of special education, as it defines inclusive education [3]. The goal, then, is to develop inclusive education systems in which schools can teach all children in their communities. Generally speaking, regular schools with a holistic orientation are the most effective against discriminatory trends. They create welcoming and inclusive society and achieve goals of education for all. Moreover, they provide effective education for the majority of individuals and ultimately improve efficiency and cost-effectiveness.

Regarding inclusive education as openness, diversity, and globalization, we argue that the definition of inclusive education has been misunderstood by many instructors and that the spirit of inclusive education has been insufficiently promoted, failing to ensure that the disability is not in the body but in the mind and that critical thinking and innovation address the challenges in the surrounding environment. Regarding the strategies of people of determination and what specialized scientists have proposed to UNESCO: "When we talk about diversity, we are not referring to students with special educational needs, pupils in trouble, or immigrants or highly gifted children; We are referring not only to teacher support but to a support system, not only to a special program for schools but to a flexible curriculum fit for diversity" [4]. Hence, despite significant international efforts made in the last 25 years to desegregate and deinstitutionalize students with or without disabilities, research has shown that levels at which inclusive education is practiced is far from acceptable.

In the UAE, education has generally faced several challenges, including the multiplicity and diversity of students, educational institutions, and curricula. The most important and most difficult challenges are the school environment itself, traditional education methods, weak professional teaching qualifications, lack of development for effective curricula, evaluation criteria problem, and inadequate student counselling facilities [5]. In addition to the contradiction in educational trends between the various school institutions in the country rather than their education, it is necessary to stimulate the role of the family in achievement and self-confidence and to consolidate the principles of citizenship and a culture of moderation and tolerance [6].

This study aimed to identify the social and psychological effects of inclusion among people with hearing disabilities. The study participants included deaf and hard-of-hearing students in the Resources Centre for Disability at the University of Sharjah.

\subsection{The Objectives of the Study}

The study's main objective was to identify the social and psychological effects of inclusive education on students with hearing disabilities. Subobjectives included the following:

1. to identify the social and psychological effects of inclusive education processes on deaf and hard-of-hearing students;

2. to identify the relationships between social interaction and psychological interaction;

3. to identify the differences between deaf and hard-of-hearing students on how inclusive education affects psychological adjustment and social interaction;

4. to identify the main challenges that students encounter during the process of inclusive education.

\subsection{Study Hypotheses}

The hypotheses were thus formulated as follows:

Hypothesis 1. Gender, educational level, age, and disability type are correlated with psychological adaptation and social interaction.

Hypothesis 2. There are differences in psychological adaptation between deaf and hard-of- hearing students.

Hypothesis 3. Inclusion affects the social interaction of DHHS. 
In this context, a study by Dev and Kumar [7] on the inclusion of people with disabilities in Indian and Pakistani schools in Abu Dhabi and Dubai indicated that special education is currently considered individualistic, and it will be difficult for teachers to eliminate this perception. Researchers have identified many factors affecting teachers' perception of education. The most important are usually recognized as skills and competence and teachers' desire. The significant factor is support from school staff. All these factors have been recognized as important aspects of integrating children with special needs in the regular classroom [8]. A study on students with disabilities in UAE schools stated that the problems of inclusive education included lack of qualified special education professionals to deal with these students, a lack of proper teacher training for mainstream classrooms, a lack of inclusion knowledge among senior-level administrators, and inadequate financial support for services specifically in private schools. The main issue was a lack of awareness of problems that students with and without disabilities face in inclusive settings [9].

Generally, the number of students with disabilities in the UAE is increasing every year [10]. The National Policy for Empowering People of Determination confirmed the increasing number of people with disabilities in the UAE. Statistics from 2016 published by the Ministry of Community Development indicated 15,782 cases of various disabilities registered as people of determination cardholders, of whom $62 \%$ were citizens [6]. The number of citizens reached 9869, while that of noncitizens reached 5913 [6]. The number of people of determination reached 23,263 between 2016 and 2019 [6], of whom 13,301 were citizens and 9962 were nonresidents. Accurate data were derived from people of determination's registration cards for services provision, as the card is the only official proof of disability in all federal, local, private, and government institutions.

During the twentieth century, targeted consideration was directed towards people with special educational needs and disabilities (SEND) because of discrimination in the education system that separated students with SEND from society [11,12]. Undoubtedly, an individual's sense of acceptance plays an important role in their successful social interaction with others, as the individual's psychological development and social behaviour are affected by the surrounding society's culture, trends, and values.

The issue of inclusion prompted extensive research in the field of disability in the United States during the 1970s, and this stipulated the necessity of providing educational and professional care methods for people with special needs [13]. Such care methods can be used with nondisabled peers to bring people with special needs into a less restricted environment with access to free or public education [14]. The main factor in the success of education in many developed countries has been the drive towards the rights of people with disabilities to access the learning process without exception. The practice of academic and inclusive education has thus become more widespread.

Many studies have confirmed that deaf and hard-of-hearing (DHH) students are capable of continuing higher education. Gallaudet College was established in 1864 in Washington, DC to provide services to deaf and hard-of-hearing students to undertake graduate studies in literary and scientific disciplines [15,16]. Germany was among the first European countries to launch initiatives for students with disabilities at higher education institutions, specifically at the University of Hamburg, which has a complete sign language training centre to facilitate the education process.

Many studies also referred to the 2006 United Nations Convention on the Rights of Persons with Disabilities [17], which called for the recognition and promotion of sign language, facilitation of sign language learning, and reinforcement of the deaf community's linguistic identity [18,19].

Sadiq [20] mentioned that the Arab world had an interest in integrating the disabled into regular schools and in the assertion of their right to equal educational opportunities to be taught with other normal peers through the Arab Declaration issued in April 1981 [21]. This has been confirmed by the UN (2019), and Arab countries have signed, ratified, or acceded to the Convention of the Rights of Persons with Disabilities (CRPD) [22]. All have adopted disability laws, and many have developed strategies and action plans. However, 
these plans are often slow to translate into practical change because of "the complexity of disability policy and also due to social stigma, which are still deeply embedded in social attitudes. The continuing exclusion of persons with disabilities is also in large part a consequence of the linkage between disability and poverty, persons who are poor are more likely to have disabilities, and persons with disabilities are more likely to become or remain poor" [23]. However, the situation cannot be generalized to all Arab countries-for instance, the United Arab Emirates have invested considerable effort by institutionalizing a new philosophical framework for disability; the "Dubai Inclusive Education Policy Framework 2017" [24,25], demonstrated a strong commitment to ensuring the educational and social inclusion of all children, adults, and families experiencing SEND.

The UAE has provided an excellent inclusive education experience since its foundation on 2 December 1971 and has diligently sought to cater to the various needs of persons with disabilities, whom it regards as an integral part of society with the same rights and obligations as other nondisabled members of the community [10]. Since 1979, the provision of special education programmes and services has evolved and accelerated rapidly in all categories of special education, with equal access to educational opportunities and availability in higher levels of education. The UAE has been swiftly advancing its support for disabled people as part of a wider effort to nurture a culture of tolerance and respect. The UAE has acceded to, and ratified, the basic international human rights instruments, mainly the International Convention on the Rights of Persons with Disabilities [10].

These are contemporary ideas of inclusive education, defined in some studies as principles of teachers understanding the nature of knowledge and apprising the students of their role in learning and of how the aforementioned ideas of knowledge and learning are presented in teaching and classwork $[26,27]$.

The National Policy for Empowering People of Determination 2020 aimed at human capacity building and for the UAE to be a world leader in the cohesion of society's nucleus, the family. This major goal for the UAE's public policy implied achieving optimal social development [6].

Within the general framework of education policy in the UAE-the educational strategic policy focused on people of determination with disabilities-the institution clarified the mechanisms used to recognize the rights of people of determination to complete university education and to take all necessary measures to ensure the completion of their higher education; to facilitate access to facilities and services related to classroom and extracurricular activities; to provide support and advice to people with disabilities; and to respect their privacy [28].

Having reviewed the international, regional, and local backgrounds and inclusion statuses of disabled students, particularly the deaf and hard of hearing, it is clear that these laws, policies, and strategies were devised to protect students with disabilities during the social inclusion process and to combat any challenges they may encounter during social interaction [29]. However, certain problems have emerged from the inclusive system that affect students' psychological adaptation and social interaction.

The study of the social and psychological effects of inclusive education is relevant and practically significant for regions wherein inclusive education is rapidly developing and best practices are being from other countries, but which have short histories and little experience. The contribution of this study lies in an intermediate empirical assessment of the results of the state policy of inclusiveness at the levels of the university and specialized departments of universities that is close to the experience of not only the UAE but other countries [4]. Unlike many existing studies on this topic, this study was not about assessing a specific program, methodology, or approach to inclusive education, but about the assessment by inclusive students of the overall impact of inclusive education policies in the UAE on social interaction and psychological adaptation from their internal point of view. 


\section{Materials and Methods}

\subsection{Research Design}

The study adopted a descriptive analytical approach with a study population of 48 hearing-impaired students at Sharjah University's Disability Resource Centre. As the study was interrupted by the COVID-19 situation, an electronic questionnaire comprising 25 measurable indicators followed by an open question about the challenges faced by the study sample during the inclusive educational process was used for data collection. The 25 items assessed the effect of inclusive education on social interaction and the psychological dimensions measured using the Lecter scale (agree/neutral/disagree). In this case, the Lecter scale was used in order to provide the participants with a clear and unambiguous psychological identification of the answer, almost to the level of a bipolar division of opinions: agree or disagree. The results obtained confirmed the adequacy of this approach and the obvious redundancy of the Likert scale, because in most cases the respondents demonstrated a solidarity position on each question of the questionnaire, with few exceptions.

The questionnaire concluded with nine open-ended questions that were administered to collect quantitative and qualitative data. Subsequently, the value of the Spearman correlation coefficient for another value measured in the study (for example, between the values of social interaction and psychological adaptation) was established between the values obtained on the scale for answering the questionnaire questions. The use of Spearman's correlation was due to the facts that this method is designed to search for the proximity of two groups of values, one or both of which can be rank, and that both questionnaires used the Lecter scale, which is a rank scale.

The two sets of questions (questionnaires) presented below were created specifically for this study based on the experience gained by the University of Sharjah. The validity of the questionnaires was checked by reinterviewing and checking the correlation of responses using the Pearson method. The difference between the polls was one month. Also, a study of Pearson's correlation between the responses of the study group and a group of students with similar hearing impairments formed by the method of random sampling was carried out. In both cases, a strong correlation was obtained: $r=0.784$ and $r=0.761$, respectively. In terms of the results of these checks, the validity of the questionnaires could be considered satisfactory. The reliability of the questionnaires was tested using Cronbach's alpha based on the survey results demonstrated in this study. The value of Cronbach $\alpha$ equalled 0.802 . This may indicate fairly high reliability of the test used.

\subsection{Participants}

A full sample of 48 students was used to study the correlation coefficient between the social and demographic variables and the social interaction and psychological adaptation variables, as well as the correlation coefficient between social interaction and psychological adaptation. To study the effects of inclusion on psychological adaptation and social interaction, a sample of 24 deaf and hard-of-hearing students without any other disabilities was used. Students with other disabilities, such as impaired vision, impaired mobility, learning difficulties, complex disability, and autism, were excluded. Considering the size of the general population of the sample (students with hearing impairments in Sharjah University's Disability Resource Centre), the admissible sampling error did not exceed 3.9, which allowed the sample to be considered statistically representative.

Table 1 shows the demographic structure of the sample. 
Table 1. The demographic and social characteristics of the deaf and hard-of-hearing Students.

\begin{tabular}{|c|c|c|c|c|c|}
\hline $\begin{array}{l}\text { 1-Kind of } \\
\text { Disability }\end{array}$ & \multicolumn{2}{|c|}{ Partially Deaf } & \multicolumn{2}{|c|}{ Deaf } & Total \\
\hline Frequency & \multicolumn{2}{|c|}{7} & \multicolumn{2}{|c|}{17} & 24 \\
\hline Percentage & \multicolumn{2}{|c|}{29.2} & \multicolumn{2}{|c|}{70.8} & 100 \\
\hline 2-Gender & \multicolumn{2}{|c|}{ Male } & \multicolumn{2}{|c|}{ Female } & Total \\
\hline Frequency & \multicolumn{2}{|c|}{8} & \multicolumn{2}{|c|}{16} & 24 \\
\hline Percentage & \multicolumn{2}{|c|}{33.3} & \multicolumn{2}{|c|}{66.7} & 100 \\
\hline 3-Age & $<25$ & 25-35 & $35-45$ & $\geq 45$ & Total \\
\hline Frequency & 10 & 1 & 10 & 3 & 24 \\
\hline Percentage & 41.7 & 4.2 & 41.7 & 12.5 & 100.1 \\
\hline $\begin{array}{l}\text { 4-Education } \\
\text { Level }\end{array}$ & First $\mathbf{Y}$ & Second Y & Third Y & Fourth Y & Total \\
\hline Frequency & 15 & 4 & 1 & 4 & 24 \\
\hline Percentage & 62.5 & 16.65 & 4.2 & 16.65 & 100 \\
\hline
\end{tabular}

\subsection{Ethical Issues}

All participants agreed to participate in the study on an anonymous basis. Their profiles and email addresses were randomly associated with identifiers to ensure the confidentiality of the survey. No personal data of the participants were collected or processed during the study.

\subsection{Data Collection}

Polls involving 24 and 48 respondents were conducted simultaneously using different questionnaires. The questionnaires were sent to the respondents all at the same time, by agreement with the participants. After the return of completed questionnaires, the questionnaires were statistically and analytically processed using a statistical analysis program.

\subsection{Statistical Processing}

The Statistical Package for the Social Sciences (SPSS) was used for statistical processing of the collected data.

\subsection{Research Limitations}

The study was conducted on a small group of participants representing only one of the special training centres for people with disabilities in the UAE. The results need to be clarified in relation to the correlation of sex and age in the future. Also, the study focused mainly on only one type of hearing impairment, while in people with other types of impairment, differing correlations could be found on the same scales.

\section{Results}

Table 2 shows results verifying the study's high reliability and above-average validation for the effect of inclusion on psychological adaptation as equal to 0.88 and 0.94 , respectively. The reliability for the effect of inclusion on social interaction was 0.8 , and the validation value was 0.89 . The reliability and validation values of all factors were 0.91 and 0.95 , respectively, while the reliability and validation were average. 
Table 2. Reliability, validation, and correlation coefficients of social interaction and psychological adaptation.

\begin{tabular}{|c|c|c|c|c|c|}
\hline \multicolumn{4}{|c|}{ Reliability and Validation } & \multicolumn{2}{|c|}{ Spearman's Rho } \\
\hline Factor & No. of Terms & Reliability & Validation & Factor & Values \\
\hline $\begin{array}{l}\text { Effect of Inclusion on } \\
\text { Psychological } \\
\text { Adaptation }\end{array}$ & 12 & 0.88 & 0.94 & \multirow[t]{2}{*}{$\begin{array}{l}\text { Correlation } \\
\text { Coefficient }\end{array}$} & \multirow[t]{2}{*}{0.406} \\
\hline $\begin{array}{l}\text { Effect of Inclusion on } \\
\text { Social Interaction }\end{array}$ & 13 & 0.8 & 0.89 & & \\
\hline Total & 25 & 0.91 & 0.95 & Sig. & 0.049 \\
\hline
\end{tabular}

Table 2 also presents the Spearman's correlation coefficient value, which was equal to 0.406 , clearly a positive and weak correlation. The significance was equal to 0.04 , that is, less than 0.05 statistical significance.

Table 3 presents the results related to hypothesis 1 (the correlation coefficient between the variables of gender, educational level, age, and disability type and those of psychological adaptation and social interaction).

Table 3 reveals the results related to gender and social interaction variables, which were independent, and no correlation coefficient existed between them. Concerning gender and psychological adaptation, the results indicated that the two variables were independent, meaning that no correlation coefficient existed between them. Regarding the disability type and psychological adaptation variables, the two variables were not independent, and a correlation coefficient existed between them. Regarding disability type and social interaction, the two variables were independent, and no correlation coefficient existed between them.

The age and social interaction variables were independent, and there was no correlation coefficient between them. Regarding age and psychological adaptation, the two variables were independent, and no correlation coefficient existed between them. Education level and psychological adaptation were not independent, and a correlation coefficient existed between them. The results related to educational level and social interaction also indicated that the two variables were not independent, and a correlation coefficient existed between them.

The results showed that inclusive education affects psychological adjustment and social interaction in DHHS. Regarding the first hypothesis statement and fifth question (inclusion affects psychological adaptation), statistically significant differences of less than 0.05 with a $95 \%$ confidence interval were found in favour of those who agreed that inclusion affects psychological adjustment. Regarding the second hypothesis and sixth question (inclusion affects social interaction), statistically significant differences of less than 0.05 with a $95 \%$ confidence interval were found in favour of those who agreed that inclusion affects social interaction.

Statistically significant differences of less than 0.05 were observed, confirming that inclusion affects psychological adjustment because it contributes to DHHS' self- confidence in dealing with others. The critical probability value was less than 0.05 , indicating statistically significant differences of less than 0.05 with $95 \%$ confidence that inclusion helps to develop DHHS' self-confidence in dealing with others. These results corroborate the findings of a past study that noted that inclusion helps students learn how to interact, communicate, develop friendships, work together, and assist each other based on their individual strengths and needs [30].

Table 4 presents the results pertaining to question 2 (What are the psychological effects of inclusive education on deaf and hard-of-hearing students?) and hypothesis no. 2. A statistically significant difference of 0.004-less than 0.05-existed for those students who believed that inclusion affects students' psychological adaptation. 
Table 3. Results of correlation coefficients between the social and demographic variables and the social interaction and psychological adaptation variables.

\begin{tabular}{|c|c|c|c|c|c|c|c|c|c|c|c|}
\hline \multirow{2}{*}{$\begin{array}{l}\text { Variable } \\
\text { Gender }\end{array}$} & \multicolumn{5}{|c|}{ Social Interaction } & \multirow{2}{*}{$\begin{array}{c}\text { Variable } \\
\text { Disability }\end{array}$} & \multicolumn{5}{|c|}{ Social Interaction } \\
\hline & Neutral & Agree & Total & Chi & Sig & & Neutral & Agree & Total & Chi & Sig \\
\hline Male & 0 & 8 & 8 & \multirow{3}{*}{0.522} & \multirow{3}{*}{0.470} & $\begin{array}{l}\text { Partially } \\
\text { Deaf }\end{array}$ & 1 & 6 & 7 & 2.534 & 0.111 \\
\hline Female & 1 & 15 & 16 & & & Deaf & 0 & 17 & 17 & & \\
\hline Total & 1 & 23 & 24 & & & Total & 1 & 23 & 24 & & \\
\hline Variable & \multicolumn{5}{|c|}{ Psychological Adaptation } & Variable & \multicolumn{5}{|c|}{ Psychological Adaptation } \\
\hline Gender & Neutral & Agree & Total & Chi & Sig & Disability & Neutral & Agree & Total & Chi & Sig \\
\hline Male & 0 & 8 & 8 & 3.158 & 0.076 & $\begin{array}{l}\text { Partially } \\
\text { Deaf }\end{array}$ & 4 & 3 & 7 & 7.9 & 0.616 \\
\hline Female & 5 & 11 & 16 & & & Deaf & 1 & 16 & 17 & & \\
\hline Total & 5 & 19 & 24 & & & Total & 5 & 19 & 24 & & \\
\hline Variable & \multicolumn{5}{|c|}{ Social Interaction } & Variable & \multicolumn{5}{|c|}{ Social Interaction } \\
\hline $\begin{array}{l}\text { 1-Age } \\
\text { range }\end{array}$ & Neutral & Agree & Total & Chi & Sig & $\begin{array}{l}2- \\
\text { Educational } \\
\text { Level }\end{array}$ & Neutral & Agree & Total & Chi & Sig \\
\hline$<25$ & & 9 & 10 & 1.461 & 0.091 & First & 0 & 15 & 15 & \multirow{5}{*}{24} & \multirow{5}{*}{0} \\
\hline $25-35$ & 0 & 1 & 1 & & & Second & 0 & 4 & 4 & & \\
\hline $35-45$ & 0 & 10 & 10 & & & Third & 1 & 0 & 1 & & \\
\hline$\geq 45$ & 0 & 3 & 3 & & & Fourth & 0 & 4 & 4 & & \\
\hline Total & 1 & 23 & 24 & & & Total & 1 & 23 & 24 & & \\
\hline Variable & \multicolumn{5}{|c|}{ Psychological Adaptation } & Variable & \multicolumn{5}{|c|}{ Psychological Adaptation } \\
\hline $\begin{array}{l}\text { 1-Age } \\
\text { range }\end{array}$ & Neutral & Agree & Total & Chi & Sig & $\begin{array}{c}2- \\
\text { Educational } \\
\text { Level }\end{array}$ & Neutral & Agree & Total & Chi & Sig \\
\hline$<25$ & 4 & 6 & 10 & \multirow{5}{*}{3.992} & \multirow{5}{*}{0.262} & First & 2 & 13 & 15 & \multirow{5}{*}{7.4} & \multirow{5}{*}{0.05} \\
\hline $25-35$ & 0 & 1 & 1 & & & Second & 0 & 4 & 4 & & \\
\hline $35-45$ & 1 & 9 & 10 & & & Third & 1 & 0 & 1 & & \\
\hline$\geq 45$ & 0 & 3 & 3 & & & Fourth & 2 & 2 & 4 & & \\
\hline Total & 5 & 19 & 24 & & & Total & 5 & 19 & 24 & & \\
\hline
\end{tabular}

Table 4 shows that $79.2 \%$ of deaf and hard-of-hearing students agreed that inclusion affects psychological adjustment. This effect was clearly reflected in the $91.7 \%$ of students who agreed that inclusion enhances their self-confidence in dealing with others. A moderate $66.6 \%$ of the deaf and hard-of-hearing students reported feelings of aggression towards themselves. The results pertaining to hypothesis 1 (regarding the effect of inclusive education on the psychological adaptation of deaf and hard-of-hearing students) showed that the significance value was 0.004 and less than 0.05 . Thus, the null hypothesis was rejected, indicating statistically significant differences for the DHH who believed that inclusive education has effect on the psychological adaptation.

Table 5 presents the results relating to hypothesis 2 . A statistically significant difference value of 0.00 - less than 0.05 - existed for those who believed that inclusion affects the social interaction of the deaf and hard-of-hearing students. 
Table 4. Results on the effect of inclusion on psychological adaptation.

\begin{tabular}{|c|c|c|c|c|c|c|c|c|c|c|}
\hline No & Questions & Standard & Agree & Neutral & Disagree & $\begin{array}{l}\text { Weighted } \\
\text { Mean * }\end{array}$ & $\begin{array}{c}\text { Std. } \\
\text { Deviation }\end{array}$ & Chi & Sig & Result \\
\hline \multirow{2}{*}{1} & \multirow{2}{*}{$\begin{array}{l}\text { Inclusion improves my adaptive } \\
\text { behaviour with others. }\end{array}$} & Frequency & 23 & 1 & 0 & \multirow{2}{*}{2.88} & \multirow{2}{*}{0.338} & \multirow{2}{*}{13.5} & \multirow{2}{*}{0} & \multirow{2}{*}{ Agree } \\
\hline & & Percent & 87.5 & 12.5 & 0 & & & & & \\
\hline \multirow{2}{*}{2} & \multirow{2}{*}{$\begin{array}{l}\text { Inclusion contributes to my } \\
\text { self-confidence in dealing with others. }\end{array}$} & Frequency & 22 & 2 & 0 & \multirow{2}{*}{2.92} & \multirow{2}{*}{0.282} & \multirow{2}{*}{16.6} & \multirow{2}{*}{0} & \multirow{2}{*}{ Agree } \\
\hline & & Percent & 91.7 & 8.3 & 0 & & & & & \\
\hline \multirow{2}{*}{3} & \multirow{2}{*}{$\begin{array}{l}\text { Inclusion increases feelings of } \\
\text { aggression towards oneself. }\end{array}$} & Frequency & 16 & 4 & 4 & \multirow{2}{*}{2.50} & \multirow{2}{*}{0.780} & \multirow{2}{*}{12} & \multirow{2}{*}{0.002} & \multirow{2}{*}{ Agree } \\
\hline & & Percent & 66.7 & 16.7 & 16.7 & & & & & \\
\hline \multirow{2}{*}{4} & \multirow{2}{*}{$\begin{array}{l}\text { Inclusion increases feelings of } \\
\text { aggression towards others. }\end{array}$} & Frequency & 18 & 1 & 5 & \multirow{2}{*}{2.54} & \multirow{2}{*}{0.833} & \multirow{2}{*}{19.75} & \multirow{2}{*}{0} & \multirow{2}{*}{ Agree } \\
\hline & & Percent & 75 & 4.2 & 20.8 & & & & & \\
\hline \multirow{2}{*}{5} & \multirow{2}{*}{$\begin{array}{l}\text { Inclusion reduces my sense of being } \\
\text { distinguished from others. }\end{array}$} & Frequency & 19 & 2 & 3 & 267 & 0.702 & 22.75 & 0 & Agree \\
\hline & & Percent & 79.2 & 8.3 & 12.5 & & & & & \\
\hline 6 & Inclusion improves my attitudes & Frequency & 20 & 3 & 1 & 2.79 & 0.509 & 27.25 & 0 & Agree \\
\hline & & Percent & 83.3 & 12.5 & 4.2 & & & & & \\
\hline 7 & Inclusion increases my self- & Frequency & 21 & 1 & 2 & 279 & 0.588 & 3175 & 0 & Agree \\
\hline 7 & & Percent & 87.5 & 4.2 & 8.3 & & & & & \\
\hline 8 & Inclusion reduces the chances of & Frequency & 19 & 3 & 2 & 2.71 & 0.624 & 22.75 & 0 & Agree \\
\hline & & Percent & 79.2 & 12.5 & 8.3 & & & & & \\
\hline 9 & Inclusion contributes to the & Frequency & 21 & 3 & 0 & 288 & 338 & 1250 & 0 & A oree \\
\hline & $\begin{array}{c}\text { development of a positive image } \\
\text { about me. }\end{array}$ & Percent & 87.5 & 12.5 & 0 & 2.88 & 0.338 & & 0 & \\
\hline 10 & Inclusion provides others with & Frequency & 20 & 2 & 2 & 275 & 0608 & 2700 & 0 & A oree \\
\hline 10 & $\begin{array}{c}\text { special information about my nature } \\
\text { of my personal characteristics. }\end{array}$ & Percent & 83.3 & 8.3 & 8.3 & 2.75 & 0.608 & 27.00 & 0 & \\
\hline 11 & Inclusion reduces the amount of & Frequency & 19 & 1 & 4 & 2.63 & 0.770 & 23.25 & 0 & Agree \\
\hline 11 & special attention I need. & Percent & 79.2 & 4.2 & 16.6 & 2.03 & $0.7 / 0$ & 23.20 & 0 & \\
\hline 12 & Inclusion fosters satisfaction with & Frequency & 22 & 2 & 0 & 292 & 0282 & 16.66 & 0 & Agree \\
\hline & & Percent & 91.7 & 8.3 & 0 & & & & & \\
\hline 13 & Effect of inclusion on psychological & Frequency & 19 & 5 & 0 & 2.79 & 0.514 & 8.16 & 0.004 & Agree \\
\hline & & Percent & 79.2 & 20.8 & 0 & & & & & \\
\hline
\end{tabular}

* The weighted value in relation to the final aggregated result (column "Result" with possible values "Agree/Disagree/Neutral"), taking into account the number of answers that differed from those that formed the final result in the "Result" column. 
Table 5. Effect of inclusion on social interaction.

\begin{tabular}{|c|c|c|c|c|c|c|c|c|c|c|}
\hline No & Questions & Standard & Agree & Neutral & Disagree & $\begin{array}{l}\text { Weighted } \\
\text { Mean* }\end{array}$ & $\begin{array}{l}\text { Std. De- } \\
\text { viation }\end{array}$ & Chi & Sig & Agree \\
\hline \multirow{2}{*}{1} & \multirow{2}{*}{$\begin{array}{l}\text { Inclusion increases social } \\
\text { interaction with students' } \\
\text { peers. }\end{array}$} & Frequency & 20 & 4 & 0 & \multirow{2}{*}{2.83} & \multirow{2}{*}{0.381} & \multirow{2}{*}{10.67} & \multirow{2}{*}{0.001} & \multirow{2}{*}{ Agree } \\
\hline & & Percent & 83.3 & 16.7 & 0 & & & & & \\
\hline \multirow{2}{*}{2} & \multirow{2}{*}{$\begin{array}{c}\text { Inclusion develops } \\
\text { communication skills between } \\
\text { me and others. }\end{array}$} & Frequency & 22 & 2 & 0 & \multirow{2}{*}{2.92} & \multirow{2}{*}{0.282} & \multirow{2}{*}{16.66} & \multirow{2}{*}{0} & \multirow{2}{*}{ Agree } \\
\hline & & Percent & 91.7 & 8.3 & 0 & & & & & \\
\hline \multirow{2}{*}{3} & \multirow{2}{*}{$\begin{array}{l}\text { Inclusion enhances my } \\
\text { capacity for social coexistence. }\end{array}$} & Frequency & 22 & 2 & 0 & \multirow{2}{*}{2.92} & \multirow{2}{*}{0.282} & \multirow{2}{*}{16.66} & \multirow{2}{*}{0} & \multirow{2}{*}{ Agree } \\
\hline & & Percent & 91.7 & 8.3 & 0 & & & & & \\
\hline \multirow{2}{*}{4} & \multirow{2}{*}{$\begin{array}{l}\text { Inclusion exposes me to abuse } \\
\text { by others. }\end{array}$} & Frequency & 18 & 3 & 3 & \multirow{2}{*}{0.711} & \multirow{2}{*}{18.75} & \multirow{2}{*}{0} & \multirow{2}{*}{0.711} & \multirow{2}{*}{ Agree } \\
\hline & & Percent & 75 & 12.5 & 12.5 & & & & & \\
\hline \multirow{2}{*}{5} & Inclusion brings me different & Frequency & 19 & 5 & 0 & 279 & 0.415 & 8.16 & 0.004 & Agree \\
\hline & & Percent & 79.2 & 20.8 & 0 & & & & & \\
\hline 6 & Inclusion develops my social & Frequency & 21 & 3 & 0 & 2.88 & 0.338 & 13.50 & 0 & Agree \\
\hline 0 & & Percent & 87.5 & 12.5 & 0 & 2.00 & 0.000 & 15.00 & 0 & Agte \\
\hline 7 & Inclusion helps me enhance my & Frequency & 22 & 1 & 1 & 2.88 & 0.448 & 36.75 & 0 & Agree \\
\hline & & Percent & 91.7 & 4.2 & 4.2 & & & & & \\
\hline 8 & Inclusion allows me to provide & Frequency & 21 & 3 & 0 & 280 & A 230 & 1250 & 0 & A oree \\
\hline & $\begin{array}{c}\text { educational services that } \\
\text { satisfy my needs. }\end{array}$ & Percent & 87.5 & 12.5 & 0 & 2.00 & 0.338 & 13.50 & 0 & 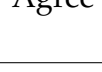 \\
\hline 9 & Inclusion helps solve many of & Frequency & 20 & 2 & 2 & 2.75 & 0.608 & 27.00 & 0 & Agree \\
\hline & & Percent & 83.3 & 8.3 & 8.3 & & & & & \\
\hline 10 & Inclusion limits the delivery of & Frequency & 20 & 2 & 2 & & 0608 & & 0 & Agr \\
\hline & $\begin{array}{l}\text { regulatory services that } 1 \text { need } \\
\text { to the required level. }\end{array}$ & Percent & 83.3 & 8.3 & 8.3 & 2.15 & 0.608 & 27.00 & 0 & \\
\hline 11 & Inclusion offers equal & Frequency & 22 & 1 & 1 & 288 & 0.448 & 3675 & 0 & Agree \\
\hline & $\begin{array}{l}\text { educational opportunities with } \\
\text { my peer groups. }\end{array}$ & Percent & 91.7 & 4.2 & 4.2 & & & & & \\
\hline 12 & Inclusion contributes to my & Frequency & 22 & 2 & 0 & 2.92 & 0.282 & 16.66 & 0 & Agree \\
\hline & & Percent & 91.7 & 8.3 & 0 & & & & & \\
\hline 13 & Inclusion strengthens my & Frequency & 22 & 2 & 0 & 292 & 0?8? & 1666 & (0 & Agrt \\
\hline & $\begin{array}{l}\text { feeling of social responsibility } \\
\text { towards others. }\end{array}$ & Percent & 91.7 & 8.3 & 0 & 2.92 & $0 . \angle 8 \angle$ & 16.66 & U & \\
\hline 14 & Effect of inclusion on social & Frequency & 23 & 1 & 0 & 2.96 & 0.204 & 20.17 & 0 & Agree \\
\hline & & Percent & 87.5 & 12.5 & 0 & & & & & \\
\hline
\end{tabular}

* The weighted value in relation to the final aggregated result (column "Result" with possible values "Agree/Disagree/Neutral"), taking into account the number of answers that differed from those that formed the final result in the "Result" column.

Table 5 reveals the effects of inclusion on social interaction. The correlation coefficient was strong at $87.5 \%$. Excellent social interaction was evident in terms of reinforcing social responsibility towards others, developing communication skills, and enhancing the capacity for social coexistence. Most (91.7\%) agreed that inclusion contributes to their special abilities, followed by $87.5 \%$ who agreed that inclusion develops social skills. The lowest effect, at $75 \%$, was in response to the idea that inclusion exposes students to abuse by others.

Table 5 also shows the results pertaining to hypothesis 2 (regarding social interaction), in which the significance value was 0.00 - less than 0.05 - and hence the null hypothesis was rejected. Therefore, a statistically significant difference existed in favour of DHHS agreeing with the statements presented on the measurement scale. Statistically significant 
differences of less than 0.05 were observed with a $95 \%$ confidence interval in favour of those who agreed that inclusion affects social interaction.

\section{Discussion}

The study found that inclusion affected the psychological compatibility of deaf and hard-of-hearing students considerably with respect to self-confidence, especially in dealing with others, and strengthened their satisfaction with society. Total inclusion had minimal effect in increasing aggression towards oneself or others. Overall, the results indicated that inclusive education affected psychological compatibility.

Regarding the second study question, the effects of inclusive education processes on DHHS were particularly high with respect to social interaction and the development of communication skills between students and others, indicating that integration enhances students' capacity for social coexistence. It enhances practical skills, while inclusion was found to provide equal educational opportunities with peers, contributes to the benefit of special abilities, and increases a sense of social responsibility towards others. The lowest observed impact was the exposure of students to abuse by others. Inclusion had a positive effect on social interaction, compared to its impact on psychological dimensions, with the results showing that the social effect was higher than the psychological effect. Most effects revealed that inclusion enhanced social interaction, and the findings were consistent with those of Schaefer et al. [31], who observed that inclusive education had a positive effect on children's social interaction. Findings related to demographic and social characteristics indicated that university educational level showed a positive correlation between the psychological adjustment and social interaction variables because they were not independent. Regarding the disability variable, correlation was observed with psychological adaptation but not with social interaction.

The results related to the gender and age variables revealed no correlation between age and gender and psychological adaptation or social interaction because the variables were independent. Our findings were consistent with those of Hakam Al Khatab [26], which showed no statistically significant differences in the psychological adjustment of integrated or nonintegrated students according to the variables of gender, degree of disability, and grade.

Inclusive education in Sharjah University increased self-confidence and helped DHHS to make friends. This was consistent with the findings of a study by Abery et al. [32], which indicated that inclusive groups allowed children with disabilities to form solid friendships and to develop their self-confidence and sense of belonging and promote their communication skills and better emotional functioning.

Statistically significant differences of less than 0.05 were observed with a $95 \%$ confidence interval in favour of those who agreed that inclusion affects social interaction. These results corroborated those of Hassan et al. [33], which showed that the most important results were those that were holistic, such as increasing social interaction among students with and without disabilities. Students with disabilities can feel competent and capable, which enables them to acquire higher achievements and new skills [33]. Inclusive classrooms at University of Sharjah are idealized experiences directed towards self-development and social skills for deaf and hard-of-hearing students. These results all highlight the role of cooperation with families as well as with students in educational programs for comprehensive inclusion, as families provide vital support to teachers [33].

The Sharjah University DHHS' experiences with inclusive education were mostly positive with respect to the curriculum, which they largely agreed to be easy and appropriate, to meet all their needs, and to fit their cognitive capabilities. The results indicated that one of the benefits of inclusive education is its effect of increasing academic achievement levels, adding more knowledge and new information. As a means of communication, sign language is improved, and there is an interpreter who can help with the entire educational process. The results of this study were consistent with those of Collins et al. [34], who stated that inclusive classrooms are expected to increase the opportunities of students in 
social perspectives and improve academic performance and learning outcomes for students who are academically challenged [35,36].

Regarding the university staff and administrators who are responsible for the inclusive educational operation system, DHHS said that almost all of them had positive attitudes; understood the needs of DHHS; were excellent, knowledgeable, and interacting; and were aware of the rights of DHHS. Inclusive education provides opportunities for students to receive educational and academic support and academic advisory work, and there is high consideration for psychological support. The results of this study are confirmed by studies that showed that inclusive education/mainstreaming has been promoted on valuable bases: the rights of children to be included in mainstream education and the hypothesis that inclusive education is more effective [37].

Concerning the concept of social inclusion, DHHS reflected the presence of an excellent mutual level of understanding between DHHS and their ordinary peers. There is a significant level of cooperation in learning process, and deep social relations and friendships exist among DHHS, ordinary students, and interpreters. This view was also fostered by Laws and Millward [38] and Dijkhuis et al. [39], who showed that positive teacher-parent communication and collaboration are important to inclusive education, as teamwork often leads to more positive views of inclusion for both parents and teachers and the existence of distinguished friendships between all DHHS and ordinary peer students. There was a very good level of communication between students and the sign language interpreters. This is consistent with the findings of a research group that indicated that inclusive class settings allow children with disabilities to meet a variety of people and form friendships that lend themselves to a sense of belonging, thereby increasing self-esteem and self-confidence [32].

Regarding experience of a few universities' services, especially in the field of rehabilitation and development services, DHHS had increased senses of security, safety, constancy; opportunities for high-level participation in the activities, events, and initiatives held by the university; and opportunities to attend training courses, workshops, awareness lectures, and other services, all of which has a significant impact on the transmission of the inclusive education culture and positive happiness. The results of this study corroborate the results of studies that reported increasing participation rates of individuals with disabilities in school thanks to inclusion. These individuals have satisfying employment and recreation activities. Proper supports are needed in these environments to encourage adequate self-esteem and successful social interaction [32].

In the open-ended questions, about $86.4 \%$ (19 out of 22) of the DHHS mentioned that they did not face any problems. Few (3) mentioned that the challenges facing the DHHS included the availability of sign language interpreters for all lectures. Additionally, $9 \%$ explained that sometimes, they struggled to communicate with instructors without an interpreter, as it takes time to explain lectures in sign language. Problems associated with online teaching and the difficulty of sitting examinations online due to the absence of a sign interpreter were also mentioned. Regarding the educational curriculum, according to the results of the open-ended questions, educational material should be kept concise to facilitate its reading and comprehension, and it should be explained precisely. This finding was similar to findings emphasized by McLeskey [40], who reported that over a hundred educational programs had been prepared in the United States and Canada for postsecondary education for deaf students, and the students benefited from said university educational programs, which facilitated the acquisition of academic experiences. For students with disabilities, perhaps one of the most important means of this facilitation is the provision of sign language interpreters.

\section{Conclusions}

The growing number of people with hearing impairments and the international documents adopted by the UAE and other countries on the creation of inclusive education and ensuring equal education for all people stimulate research in this area. One of the 
most important goals of inclusive education for people with disabilities is to ensure their psychological and social adaptation in society. The purpose of this study was to identify the social and psychological effects of inclusive education of students with hearing disabilities at Sharjah University's Disability Resource Centre. The study involved 48 students with hearing impairments, of which 24 students were exclusively with hearing impairments and without other impairments. For the study, an electronic questionnaire of 25 questions was compiled, the reliability and validity of which were checked before the experiment. The questionnaire concluded with nine open-ended questions that were administered to collect quantitative and qualitative data. Two psychological advisors specializing in sign language facilitated the data collection process. The research results confirmed positive correlations between inclusive education and both psychological adjustment and social interaction ( $\rho=0.406)$ and negative relationships between gender and age and both psychological adaptation and social interaction variables. A positive correlation was observed between disability type and psychological adaptation $(\rho=0.616)$, while no correlation was observed with social interaction. A statistically significant difference of less than 0.05 was found in favour of those who agreed that inclusion affects psychological adaptation. A statistically significant difference of less than 0.05 was found in favour of students who agreed that inclusion affects social interaction. Further research in this area should more deeply explore individual methods or approaches to social and psychological adaptation of people with different types of impairments.

\section{Recommendations}

The suggested recommendations are based on the findings of this study, the experience of the University of Sharjah, and the extensive academic literature dedicated to addressing socialization issues and promoting the interests of people with special needs.

- Generalize and replicate the successful experiences at the University of Sharjah regarding the inclusion of students of determination in the educational system, and allocate a special department for people with disabilities that provides all required support, services, and facilities, which will lead to the success of the experience and assist in addressing all concerns expressed by students with disabilities.

- Advocate for community partnerships between universities, government sector institutions, and the development private sector to develop and enhance all capabilities to achieve a high degree of distinction in the field of inclusive education for students of determination, based on social inclusion as one of its positive social and psychological effects, as confirmed by the present study.

- Work to raise the awareness of families, parents, administrators, and all students about the concepts of inclusive education for deaf and hard-of-hearing students at university; how to deal with the deaf and hard of hearing; and understanding, assimilating, and adopting student-centred approaches to offer participation opportunities to students to make decisions related to their needs and to promote social interaction and psychological adjustment. This can be done through leaflets, educational publications, and training workshops to contribute effectively to the education and upbringing of children.

- Stimulate various media outlets to increase their interest in persons with disabilities, particularly the deaf and hard of hearing, and the importance of their social inclusion, and to work to spread awareness among members of society.

- Strengthen capacity building for the deaf and hard-of-hearing students at university in distance learning and encourage faculty members to practice this efficiently and with high quality, particularly in how to deal with deaf and hard-of-hearing students. Focus on an educational student-centred process that encourages interaction and leads to their psychological adjustment, in addition to continuous evaluation processes, with the aim of delivering high-quality and continuous development of this process.

- $\quad$ Based on the policy trends of People of Determination (2019), encourage deaf and hard-of-hearing students to participate and should consider such students' opinions 
on educational materials that are commensurate with their abilities, because deaf and hard-of-hearing students not only need a good understanding of basic academic subjects but must develop abilities and skills that help them solve the problems and challenges they face. Encourage deaf and hard-of-hearing students' participation in decision making via their university representation.

- Encourage deaf and hard-of-hearing students to conduct applied and specialized studies and scientific research, particularly on the perspectives and attitudes of students, teachers, parents, administrators, and society on the reality of disability and individuals' general attitudes towards people with disabilities, and to present proposals and solutions to modify the others' incorrect perceptions of disability. Train them to become researchers, explorers, and analysts of their situations and to identify the challenges they and other people of determination encounter in the processes of social inclusion. Disseminate the results of these studies to all institutions and agencies concerned with matters of people of determination to reap the benefits of the results and recommendations.

Author Contributions: Conceptualization, N.B.A.Y., E.M.Y., and R.M.A.; methodology, N.B.A.Y., E.M.Y., and R.M.A.; validation, N.B.A.Y., E.M.Y., and R.M.A.; formal analysis, N.B.A.Y., E.M.Y., and R.M.A.; investigation, N.B.A.Y., E.M.Y., and R.M.A.; resources, N.B.A.Y., E.M.Y., and R.M.A.; data curation, N.B.A.Y., E.M.Y., and R.M.A.; writing-original draft preparation, N.B.A.Y., E.M.Y., and R.M.A.; writing一review and editing, N.B.A.Y., E.M.Y., and R.M.A.; visualization, N.B.A.Y., E.M.Y., and R.M.A.; supervision, N.B.A.Y., E.M.Y., and R.M.A.; project administration, N.B.A.Y., E.M.Y., and R.M.A.; funding acquisition, N.B.A.Y., E.M.Y., and R.M.A. All authors have read and agreed to the published version of the manuscript.

Funding: The research was supported by the Dean of Graduate Studies and Research at Ajman University through the Internal Research Grant (IRG) 2019-2020 for this research proposal (Ref. No. 2019-IRG-HBS-7).

Institutional Review Board Statement: The study was conducted according to the guidelines of the Declaration of Helsinki, and approved by both Ajman and Sharjha University Local Ethical Committees.

Informed Consent Statement: Informed consent was obtained from all subjects involved in the study.

Data Availability Statement: Data will be available on request.

Acknowledgments: The research team would like to express their gratitude to the Dean of Graduate Studies and Research at Ajman University for the approval of the Internal Research Grant (IRG) 2019-2020 for this research proposal (Ref. No. 2019-IRG-HBS-7). It would also like to thank the Ajman University Ethical Committee, the Head of the Disability Resource Centre at Sharjah University, the questionnaire arbitrators, the sign language specialists, the psychological advisors, and the determined students at Sharjah University. The maximum duration of the project was 12 months, and it concluded by the end of September 2020.

Conflicts of Interest: The authors declare no conflict of interest. The funders had no role in the design of the study; in the collection, analyses, or interpretation of data; in the writing of the manuscript, or in the decision to publish the results.

\section{References}

1. World Health Organization. Addressing the Rising Prevalence of Hearing Loss. 2018. Available online: https://creativecommons. org/licenses/by-nc-sa/3.0/igo (accessed on 26 July 2021).

2. Ainscow, M.; Slee, R.; Best, M. Editorial: The Salamanca Statement: 25 Years on. Int. J. Incl. Educ. 2019, 23, 671-676. [CrossRef]

3. Brown, Z.; Palaiologou, I. Inclusive practice in early childhood education. In Inclusive Education: Perspectives on Pedagogy, Policy and Practice; Brown, Z., Ed.; Routledge: New York, NY, USA, 2016; pp. 65-78.

4. UNESCO. Inclusive Education Strategy: Montenegro Inclusive Education Strategy 2019-2025; UNESCO: Podgorica, Montenegro, 2019.

5. American Psychiatric Association. Diagnostic and Statistical Manual of Mental Disorders, 5th ed.; American Psychiatric Association: Washington, DC, USA, 2013.

6. Ministry of Community Development. The UAE National Policy for Empowering People of Determination; Ministry of Community Development: Dubai, United Arab Emirates, 2020. 
7. Dev, S.; Kumar, J. Teacher's perception towards integration of learning disabled students into regular class room-A study in Dubai \& Abu Dhabi schools. Procedia Soc. Behav. Sci. 2015, 211, 605-611.

8. Ramakrishna, P. Life Skills among Students with Hearing Impairment; IOR INTERNATIONAL PRESS: Tamil Nadu, India, 2019.

9. Gaad, E. Educating Learners with Special Needs and Disabilities in the UAE: Reform and Innovation. In Education in the United Arab Emirates; Gallagher, K., Ed.; Springer: Singapore, 2019; pp. 147-159.

10. Government Law No. 2 2014; Concerning Protection of the Rights of Persons with Disabilities in the Emirate of Dubai; The Ministry of Social Affairs: Dubai, United Arab Emirates, 2014.

11. O'Keefe, D.J. Persuasion and social influence. In The International Encyclopedia of Communication Theory and Philosophy; WileyBlackwell: Hoboken, NJ, USA, 2016; pp. 1-19.

12. Täuber, S. Moralized health-related persuasion undermines social cohesion. Front. Psychol. 2018, 9, 909. [CrossRef] [PubMed]

13. Arishi, A.; Boyle, C.; Lauchlan, F. Inclusive education and the politics of difference: Considering the effectiveness of labelling in special education. Educ. Child. Psychol. 2017, 34, 9-19.

14. Alnahdi, G.H. The positive impact of including students with intellectual disabilities in schools: Children's attitudes towards peers with disabilities in Saudi Arabia. Res. Dev. Disabil. 2019, 85, 1-7. [CrossRef] [PubMed]

15. Alborno, N. The 'yes ... but' dilemma: Implementing inclusive education in Emirati primary schools. Br. J. Spec. Educ. 2017, 44, 26-45. [CrossRef]

16. Almotiri, A. Saudi deaf students post-secondary transitioning experience: A grounded theory study. Deafness Educ. Int. 2017, 19, 162-170. [CrossRef]

17. Federal Law No. 29 2006; The Rights of Persons with Special Needs; The Ministry of Social Affairs: Dubai, United Arab Emirates, 2006.

18. Cawthon, S.; Garberoglio, C.L. Research in Deaf Education: Contexts, Challenges, and Considerations; Oxford University Press: Oxford, UK, 2017.

19. Della Fina, V.; Cera, R.; Palmisano, G. The United Nations Convention on the Rights of Persons with Disabilities: A Commentary; Springer: Cham, Switzerland, 2017.

20. Sadiq, M. Inclusion of People with Special Needs in Public Education; Arab Group for Training and Publishing: Cairo, Egypt, 2014. (In Arabic)

21. Lipsky, D.K.; Gartner, A. Beyond Separate Education: Quality Education for All; Paul, H., Ed.; Brookes Publishing: Baltimore, MD, USA, 1989.

22. Committee on the Rights of Persons with Disabilities. Consideration of Reports Submitted by States Parties under Article 35 of the Convention Initial Reports of States Parties Due in 2012 United Arab Emirates. 2013. Available online: https: //www.ohchr.org/EN/HRBodies/CRPD/Pages/CRPDIndex.aspx (accessed on 26 July 2021).

23. United Nations. Disability and Development Report Realizing the Sustainable Development Goals by, for and with Persons with Disabilities; United Nations: New York, NY, USA, 2019.

24. Belrehif, F.; Karam, A.A. Dubai Inclusive Education Policy Framework; Knowledge and Human Development Authority: Dubai, United Arab Emirates, 2017.

25. Cavanagh, J.; Bartram, T.; Meacham, H.; Bigby, C.; Oakman, J.; Fossey, E. Supporting workers with disabilities: A scoping review of the role of human resource management in contemporary organisations. Asia Pac. J. Hum. Resour. 2017, 55, 6-43. [CrossRef]

26. Hakam Al Khatab, L. Psychosocial Adjustment among a Sample of Students with Visual Impairment Combined and Non-Integrated in Jordan; The Jordanian: Amman, Jordan, 2015. (In Arabic)

27. Hagiwara, M.; Amor, A.M.; Shogren, K.A.; Thompson, J.R.; Verdugo, M.A.; Burke, K.M.; Uyanik, H.; Aguayo, V. International trends in inclusive education intervention research: A literature review. Educ. Train. Autism Dev. Disabil. 2019, 54, 3-17.

28. Cresswell, J.; Creswell, J.D. Research Design: Qualitative, Quantitative and Mixed Methods Approach; Sage Publications: Thousand Oaks, CA, USA, 2003.

29. Snipstad, Ø.I.M. Inclusive education: 'making up' the normal and deviant pupil. Disabil. Soc. 2020, 35, 1124-1144. [CrossRef]

30. Heroux, J.; Peters, S. Transforming Special Education with an Inclusive, Rights-Based Approach; Oxford Research Encyclopedia of Education; Oxford University Press: Oxford, UK, 2020; Available online: https://oxfordre.com/education/view/10.1093/ acrefore/9780190264093.001.0001/acrefore-9780190264093-e-1232 (accessed on 26 July 2021).

31. Schaefer, J.M.; Cannella-Malone, H.I.; Carter, E.W. The place of peers in peer-mediated interventions for students with intellectual disability. Remedial Spec. Educ. 2016, 37, 345-356. [CrossRef]

32. Abery, B.; Legostaeva, A.; Bitova, V. Supporting inclusive community living: A person-centered approach. In Handbook on Community Living and Employment; Tich., R., Ed.; University of Minnesota: Minneapolis, MN, USA, 2019; pp. 47-56.

33. Hassan, A.E.H.; Adhabi, E.A.; Jones, L.W. The impact of inclusion setting on social interaction and psychological adjustment of students with disabilities. IJSRST 2017, 3, 121-128.

34. Collins, A.; Azmat, F.; Rentschler, R. 'Bringing everyone on the same journey': Revisiting inclusion in higher education. Stud. High. Educ. 2019, 44, 1475-1487. [CrossRef]

35. Epstein, J.L. School, Family, and Community Partnerships: Preparing Educators and Improving Schools; Routledge: New York, NY, USA, 2018.

36. Van Herwegen, J.; Ashworth, M.; Palikara, O. Parental views on special educational needs provision: Cross-syndrome comparisons in Williams syndrome, Down syndrome, and autism spectrum disorders. Res. Develop. Dis. 2018, 80, 102-111. [CrossRef] [PubMed] 
37. Seenivasan, R. Educational psychology and effectiveness of inclusive education/mainstreaming. Int. J. Indian Psychol. 2018, 6, 46-67.

38. Laws, G.; Millward, L. Predicting parents' satisfaction with the education of their child with Down's syndrome. Educ. Res. 2001, 43, 209-226. [CrossRef]

39. Dijkhuis, R.R.; Ziermans, T.B.; Van Rijn, S.; Staal, W.G.; Swaab, H. Self-regulation and quality of life in high-functioning young adults with autism. Autism 2017, 21, 896-906. [CrossRef] [PubMed]

40. McLeskey, J. Council for exceptional children, \& collaboration for effective educator development, accountability and reform. In High-Leverage Practices in Special Education; Council for Exceptional Children \& CEEDAR Center: Arlington, TX, USA, 2017 ; pp. 27-41. 